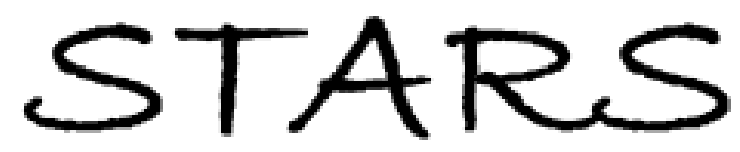

University of Central Florida

STARS

$1-1-1991$

\title{
Soft X-Ray Projection Lithography Using a 1-1 Ring Field Optical- System
}
A. A. MacDowell
J. E. Bjorkholm
J. Bokor
L. Eichner
R. R. Freeman

See next page for additional authors

Find similar works at: https://stars.library.ucf.edu/facultybib1990

University of Central Florida Libraries http://library.ucf.edu

This Article; Proceedings Paper is brought to you for free and open access by the Faculty Bibliography at STARS. It has been accepted for inclusion in Faculty Bibliography 1990s by an authorized administrator of STARS. For more information, please contact STARS@ucf.edu.

\section{Recommended Citation}

MacDowell, A. A.; Bjorkholm, J. E.; Bokor, J.; Eichner, L.; Freeman, R. R.; Mansfield, W. M.; Pastalan, J.; Szeto, L. H.; Tennant, D. M.; Wood, O. R. Il; Jewell, T. E.; Waskiewicz, W. K.; White, D. L.; Windt, D. L.; Silfvast, W. T.; and Zernike, F., "Soft X-Ray Projection Lithography Using a 1-1 Ring Field Optical-System" (1991). Faculty Bibliography 1990s. 278. https://stars.library.ucf.edu/facultybib1990/278

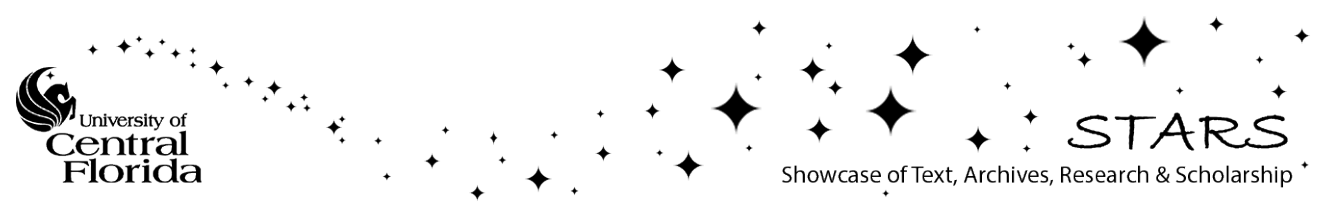




\section{Authors}

A. A. MacDowell, J. E. Bjorkholm, J. Bokor, L. Eichner, R. R. Freeman, W. M. Mansfield, J. Pastalan, L. H. Szeto, D. M. Tennant, O. R. Wood II, T. E. Jewell, W. K. Waskiewicz, D. L. White, D. L. Windt, W. T. Silfvast, and F. Zernike 


\section{Soft x-ray projection lithography using a 1:1 ring field optical system}

A. A. MacDowell, J. E. Bjorkholm, J. Bokor, L. Eichner, R. R. Freeman, W. M. Mansfield, J. Pastalan, L. H. Szeto, D. M. Tennant, O. R. Wood, T. E. Jewell, W. K. Waskiewicz, D. L. White, D. L. Windt, W. T. Silfvast, and F. Zernike

Citation: Journal of Vacuum Science \& Technology B: Microelectronics and Nanometer Structures Processing, Measurement, and Phenomena 9, 3193 (1991); doi: 10.1116/1.585315

View online: https://doi.org/10.1116/1.585315

View Table of Contents: https://avs.scitation.org/toc/jvn/9/6

Published by the American Institute of Physics 


\title{
Soft $x$-ray projection lithography using a $1: 1$ ring field optical system
}

\author{
A. A. MacDowell \\ AT\&T Bell Laboratories, 510E Brookhaven Laboratory, Upton, New York 11973
}

J. E. Biorkholm, J. Bokor, L. Eichner, R. R. Freeman, W. M. Mansfield, J. Pastalan,

L. H. Szeto, D. M. Tennant, and O. R. Wood II

AT\&T Bell Laboratories, Crawfords Corner Road, Holmdel, New jersey 07733

T.E. Jewell, W. K. Waskiewicz, D. L. White, and D. L. Windt

AT\&T Bell Laboratories, 600 Mountain Avenue, Murray Hill, New Jersey 07974

W.T. Silfvas:

University of Central Florida, Orlando, Florida 32826

F. Zernike

S. V. G. Lithography Systems, Inc., Wilton, Connecticut 06897

(Received 28 May 1991; accepted 17 July 1991)

An iridium-coated Offner 1:1 ring field camera has been used to carry out projection lithography using $42 \mathrm{~nm}$ light from an undulator in the vacuum ultra violet storage ring at Brookhaven National Laboratory. Near-diffraction-limited resolution has been obtained showing features as small as $0.2 \mu \mathrm{m}$ within a $2 \mathrm{~mm} \times 0.25 \mathrm{~mm}$ image feld. Images of both transmission and reflection masks have been obtained. The impact of source coherence on imagery has been investigated. Hydrocarbon contamination problems experienced in this photon energy range have been investigated and possible solutions are suggested.

\section{INTRODUCTION}

Soft $x$-ray projection lithography has been of interest for the last few years ${ }^{1-3}$ because the imaging resolution improves with the use of shorter wavelength while still maintaining a reasonable depth of focus. First experimental results showing diffraction-limited imagery with soft $x$ rays of wavelength $14 \mathrm{~nm}$ were obtained using the simple two-mirror Schwarzschild optical arrangement. ${ }^{4}$ Lines and spaces of dimensions $0.05 \mu \mathrm{m}$ were printed. The Schwarzschild optic has only a small image field and is not of use as a practical camera for integrated circuit (IC) manufacture.

A sightiy more complicated design that is closer to a practical IC camera is the Offner ring field optic. ${ }^{5}$ Wood et al ${ }^{6}$ calculated the optimal setup for this optic for a range of wavelengths ( $13-436 \mathrm{~nm})$. These calculations provided the basis for this experimental work using this optic at $42 \mathrm{~nm}$.

\section{A. Ring field optic}

The schematic layout of the Offner ring field optic is shown in Fig. 1. Offner ${ }^{5}$ showed that with proper design, two opposite points on an annular ring could be nearly perfectly imaged as 3rd-and 5th-order aberrations cancel within this ring. The diameter of the primary mirror is $233.6 \mathrm{~mm}$ and with a numerical aperture (NA) $=0.135$ the annular ring of good imagery has a radius of $55 \mathrm{~mm}$ and width of about $250 \mu \mathrm{m}$. The Raleigh criterion for the depth of focus and minimum feature size are \pm 1.2 and $0.16 \mu \mathrm{m}$, respectively, at $42 \mathrm{~nm}$ wavelength. Figure 2 shows the modulation transfer function (MTF) of the optic for these parameters when illuminated with incoherent radiation of $42 \mathrm{~nm}$ wavelength.
Oux choice of $42 \mathrm{~nm}$ wavelength was a compromise between our desire to use as short a wavelength as possible and the availability of suitable reflective coatings for the mirrors that could easily be deposited over the large area of active optical surfaces $\left(150 \mathrm{~cm}^{2}\right)$. The preferred choice of reflective coatings would be multilayer coatings optimized for 14 $\mathrm{nm}$, as these give the highest refiectivity in the soft $\mathrm{x}$-ray range; ${ }^{4}$ however, the technoilogy for depositing these films over large areas with adequate control is still being developed. A thin film of iridium was chosen as the mirror coating due to its high normal incidence reflectance down to short wavelength. At $42 \mathrm{~mm}$ the normal incidence reflectivity is $\approx 13 \%$.

RING-FIELD OPTICAL SYSTEM

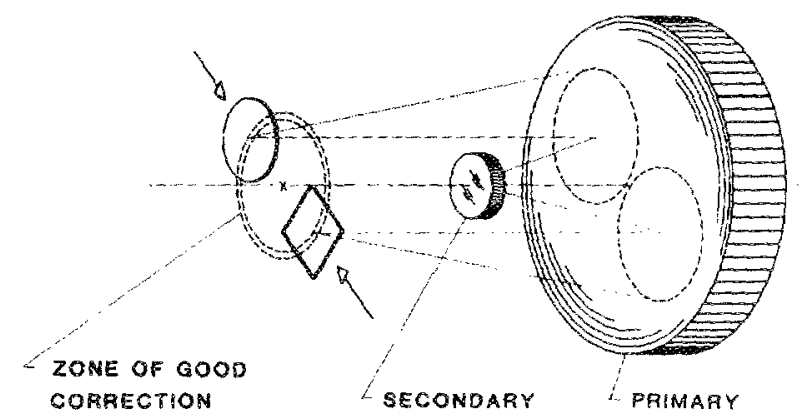

F16. 1. Schematic layout of the Offner 1:1 ring field optic. Good imagery is obtained within the annular ring of radius 55 and width $0.25 \mathrm{~mm}$. Seanning of the mask and wafer allows for imaging over a large area. 


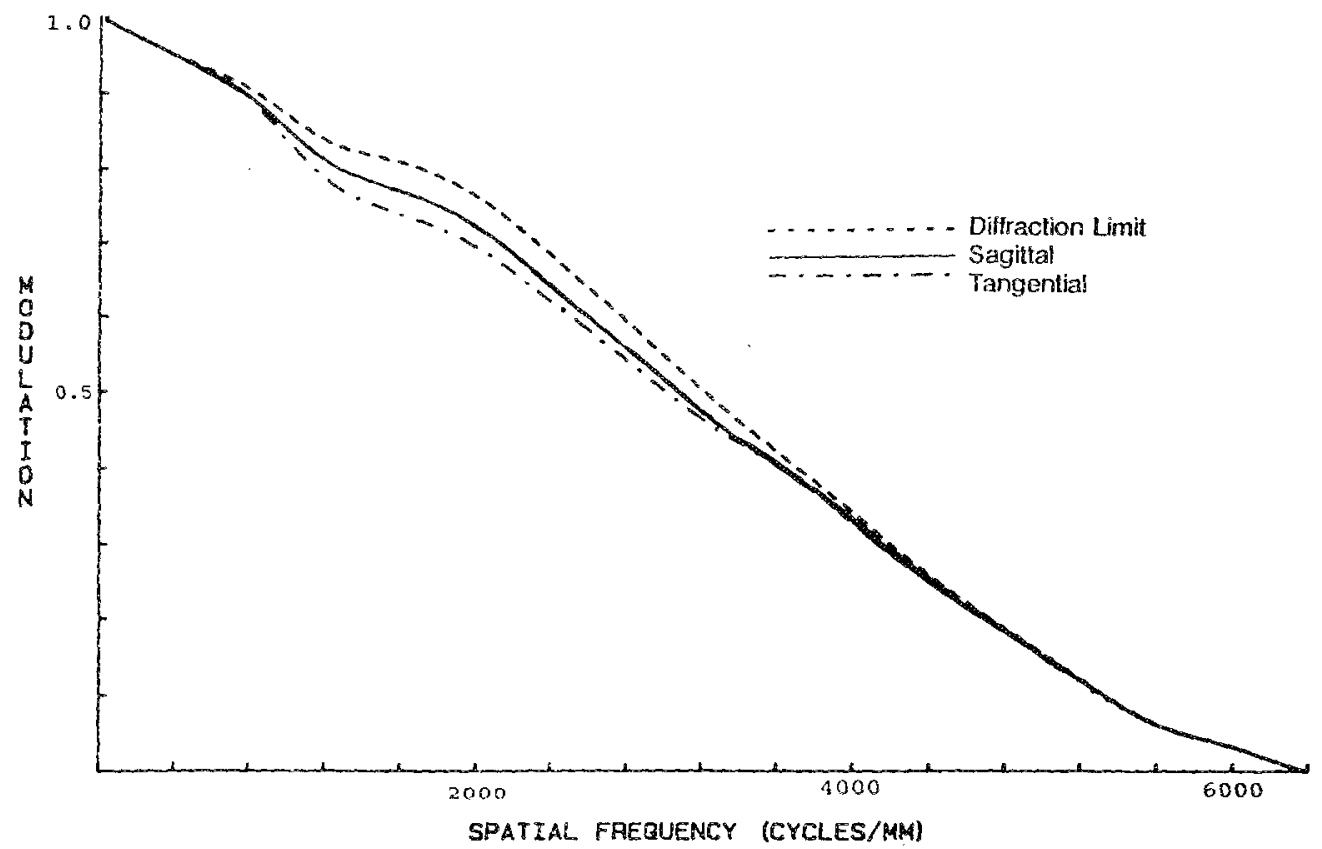

FIG. 2. Calculated diffraction based square-wave incoherent modulation tratsfer function (MTF) for the 1:1 ring field optic for $\lambda=42 \mathrm{~nm}$, $N A=0.135$. Features of size 0.16 $\mu \mathrm{m}$ have a MTF of $50 \%$.

\section{EXPERIMENTAL}

The ring field optic was supplied by Perkin-Elmer as a modified version of the Micralign PE300 projection printer. The system was modified by removing all the scanning mechanism and peripheral optics leaving only the two main mirrors in their mounting assemblies. The mirrors were coated with $17 \mathrm{~nm}$ of iridium over $6 \mathrm{~nm}$ of chromium by Acton Research. The photon source was the first harmonic of the U13 undulator at the Brookhaven Vacuum Ultraviolet (VUV) Storage Ring. ${ }^{3}$ This source provides a highly collimated beam of narrow-band radiation that can be tuned in wavelength by changing the magnet gap. The longitudinal coherence of this source is approximately $1 \mu \mathrm{m}$. All experiments were carried out in vacuum as photons of this wavelength $(42 \mathrm{~nm})$ are readily absorbed by all gasses. Figure 3 shows the calculated output of this source for fux passing through a 2-mm-diam aperture at a distance of $13 \mathrm{~m}$.

The experimental layout for the reflection mask configuration is shown in Fig. 4. The undulator source is $12 \mathrm{~m}$ from the first optical component which is a $7.5^{\circ}$ grazing incidence, water-cooled silicon mirror. This mirror acts as a low-pass filter and provides a horizontal deflection of the beam out of the path of the high-energy bremstrallung radiation which is absorbed by the lead radiation shield. The beam is filtered with an $8000-\hat{A}$-thick aluminum foll which removes the stray visible and $U V$ light from the source. Higher-energy photons are removed by the normal incidence reflections within the ring field optic itself. The beam then passes through a conduction limiter (a $2 \mathrm{~mm}$ internal diameter tube, $25 \mathrm{~cm}$ long) that separates the $10^{-6}$ Torr vacuum of the experiment from the ultrahigh vacuum of the beam line. Following the conduction limiter is a two-mirror device ("coherence buster") that rotates about the beam axis and produces a cone of radiation whose apex is a 2 -mm-diam spot (defined by the conduction limiter) on the reflection mask. The mask is thus illuminated by light from all direc- tions as defined by the surface of the cone and the radiation can then be considered to be incoherent. The cone angle is half that of the NA of the optic so the pupil of the ring field optic is filled with an annular ring of zero order light of diameter half that of the pupil diameter.

For operation with a transmission mask the ring field optic and vacuum chamber are rotated $120^{\circ}$ in a clockwise direction such that the beam of radiation passes perpendicularly through the transmission mask into the optic.

The mask and imaging wafer are 5-cm-diam silicon wafers mounted vertically against three balls in the focal plane of the optic. The balls can be independently adjusted to an accuracy $<0.1 \mu \mathrm{m}$ with respect to their distance from the imaging mirrors. In this way both the mask and wafer can be adjusted for tilt, roll, and focus. The reflection mask is in-

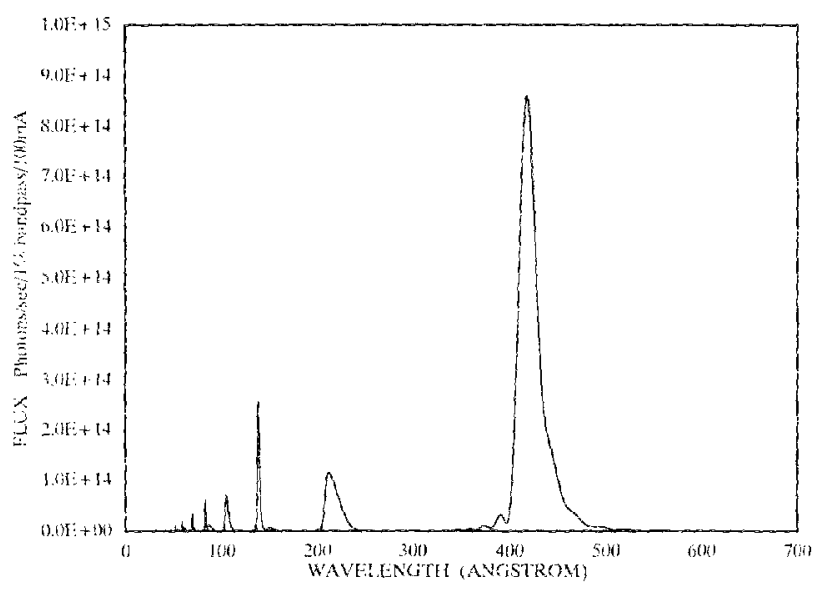

Fig. 3. Calculated total flux through a $2 \mathrm{~mm}$ aperture into the ring field experiment from the U13 undulator source at the VUV storage ring at Brookhaven National Laboratory. For these experiments we are using the 1 st harmonic at $\sim 42 \mathrm{~nm}$. The storage ring current varied between $200-700$ mA. 


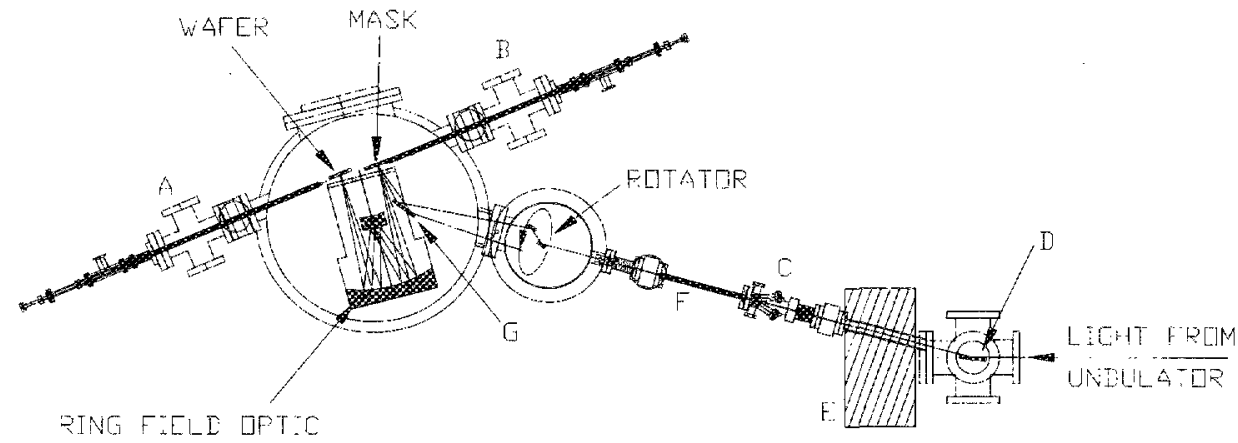

FiG. 4. Experimental arrangement for the soft $x$-ray projection experiment when using the reflection mask. (A) Load lock for wafer. (B) Load lock for mask. (C) Filter assembiy. (D) Horizontally deflecting mirror. (E) Lead radiation shield. (F) Conduction limiter. (G) Fold mirror. clined at $8^{\circ}$ to the focal plane to allow for mask illumination and allow the reflected light to enter the optic. To maintain imaging symmetry the wafer is also inclined at $8^{\circ}$. Although the ring field optic lends itself to scanning of mask and wafer in order to increase the imaging field, such a scanning device was not incorporated in these early set of experiments.

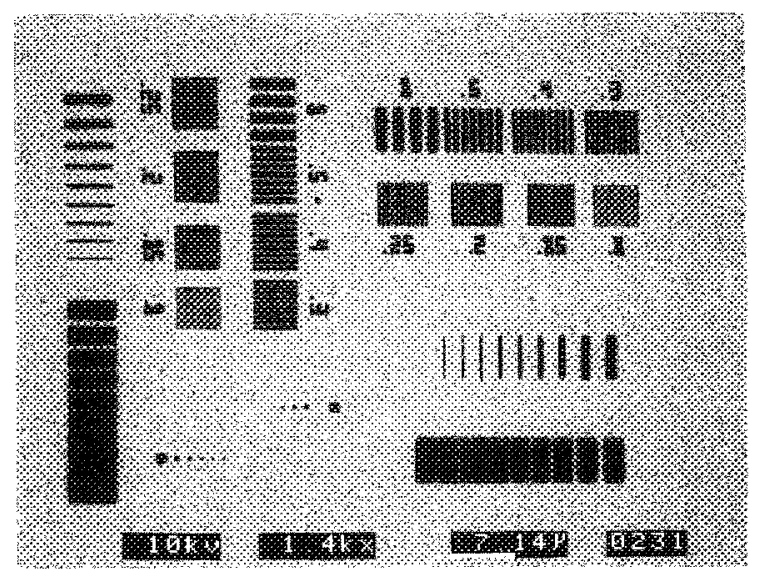

(a)

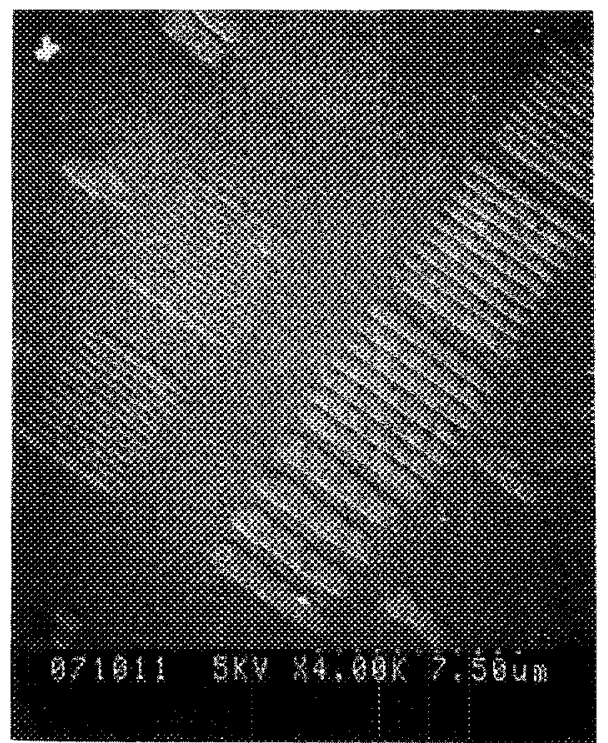

(b)

\section{RESULTS}

A scanning electron micrograph (SEM) of our transmission mask is shown in Fig. $5(\mathrm{a})$. It consists of various patterns etched through a $0.7-\mu \mathrm{m}$-thick silicon membrane. For our first set of experiments the coherence buster was not

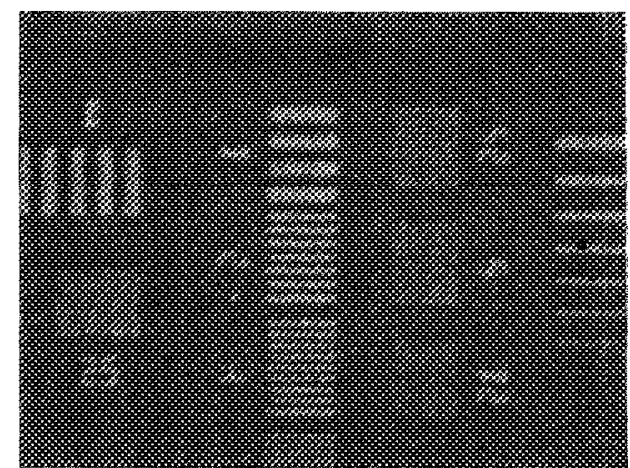

(c)

FIG. 5. (a) SEM of the open stencil transmission mask. It is etched through a 7000-A-thick silicon film. The features range in size from 0.1 to $1.0 \mu \mathrm{m}$ wide as indicated by the numerals which refer to the line-and-space dimensions in micron units. (b) SEM micrograph of the image of the transmission mask imaged by the ring field optic into $60 \mathrm{~nm}$ of PBS resist using coherent $42 \mathrm{~nm} x$-rays. The $1.0,0.5,0.4,0.3,0.25$, and $0.2 \mu \mathrm{m}$ lines and spaces are printed. The $0.15 \mu \mathrm{m}$ lines and spaces (to the upper right of the $0.2 \mu \mathrm{m}$ lines) are not printed. The exposure time was $10 \mathrm{~s}$. (c) Optical Nomarsiki micrograph of the image of the transmission mask imaged in $60 \mathrm{~nm}$ thick PES resist with incoherent illumination. The numerals are clearly resolved compared to the image formed using coherent illumination (b). Exposure time was $50 \mathrm{~s}$ which was significantly longer than for (b). This was due to carbon contamination of mirrors in the coherence buster. 
used so the illumination was highly coherent. The coherent illumination cutoff frequency for this system is $0.16 \mu \mathrm{m}$ lines and spaces, so the $0.15 \mu \mathrm{m}$ lines are not expected to be printed. Figure 5(b) shows an image of the transmission mask produced by the 1:1 ring field optic in a 60 -nm-thick layer of polybutene-1 sulfone (PBS). The $0.2 \mu \mathrm{m}$ lines and spaces are the smallest imaged. The $0.15 \mu \mathrm{m}$ lines and spaces are not printed. The lowered contrast of the $0.2 \mu \mathrm{m}$ lines and spaces compared to other lines and spaces indicate that the optic is very close to but probably not quite at the diffraction limit. The image of Fig. 5(b) is heavily overexposed as indicated by the unequal line-and-space dimensions. The overexposure was an attempt to clean out the spaces down to the silicon substrate. Scumming and granularity associated with PBS resist at these small line dimensions are readily visible. The absorption coefficient at $42 \mathrm{~nm}$ of most organic polymers is approximately $30 \mu \mathrm{m}{ }^{1}$ (Ref. 9) so the flux intensity for the bottom of the resist next to the substrate is only $16 \%$ of the initial dose. This is an unfavorable situation for resist exposure and development and accounts for the gently sloping side walls. ${ }^{10}$ Other resists tried at this wavelength were poly (methylmethacrylate) (PMMA), 2,2,2-trifluoroethyl $\alpha$-chloroacrylate (EBR-9), and Shipley SAL-605. All showed image formation comparable to PBS. PBS was found to be the most sensitive so imaging experiments were performed with PBS.

Imaging of the numerals in Fig. 5(b) is very poor. We consider that this is due to fringing artifacts associated with the use of coherent illumination. Figure 5(c) shows an optical Nomarski micrograph of the image of the transmission mask produced by the ring field optic when illuminated with incoherent radiation. In this case the coherence buster was in use with the result that the numerals are clearly imaged better. The absence of the $0.2 \mu \mathrm{m}$ features is due to vibration from the rotator. The use of the optical Nomarski microscope to record the images proved necessary as the exposure times became excessively long if the PBS was exposed to its full depth of $60 \mathrm{~nm}$. With moderate exposure the images produce only a slight undulation on the surface of the resist. The optical Nomarski technique is well suited to imaging areas of small height differences with high contrast.

Figure 6(a) is a SEM of a reflection mask consisting of a gold reflecting pattern on an absorbing silicon substrate. Reflectivities at the wavelength of $45 \mathrm{~nm}$ used are $7 \%$ for gold $^{7}$ and $0.9 \%$ for silicon. ${ }^{11}$ The reflectance contrast ratio is approximately $8: 1$. The pattern was formed by electron beam direct write in a PMMA bilayer followed by gold evaporation and lift off. The pattern is the gate level of a ring oscillator circuit. The smallest features are $0.35 \mu \mathrm{m}$. Figure $6(\mathrm{~b})$ is a Nomarski optical micrograph of the developed image in PBS. The rotator was in operation and the pattern is imaged with high fidelity.

\section{CARBON CONTAMINATION}

It became apparent early in the experiments that carbon contamination was a severe problem. The experiments were performed in a vacuum of $\sim 10^{-6}$ Torr. Soft $x$ rays irradiating a surface contaminated with hydrocarbons result in their

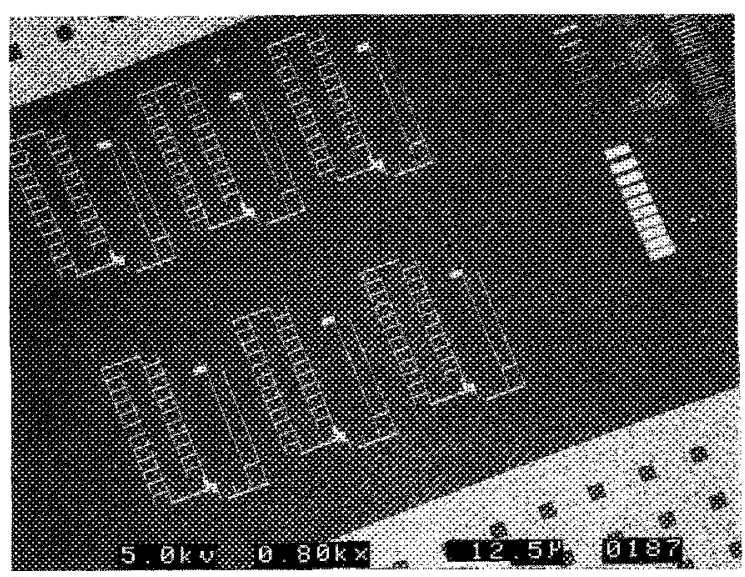

(a)

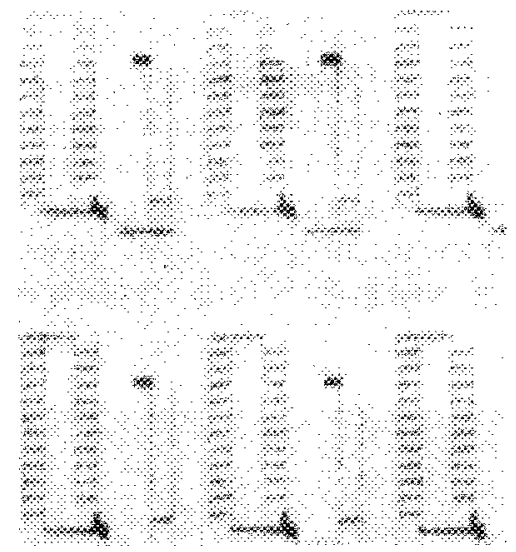

(b)

FiG. 6. (a) SEM of the reflection mask consisting of a gold pattern etched on the surface of a silicon wafer. The pattern is that of the gate level of a ring oscillator circuit. The smallest feature is $0.35 \mu \mathrm{m}$. (b) Nomarski optical micrograph of the image formed using the gold patterned reflection mask with incoherent $45 \mathrm{~nm}$ light. The image is printed in $600 \AA$ of PBS resist. Imaging time was $10 \mathrm{~min}$.

cracking and the deposition of a layer of carbon. Figure 7 shows a transmission mask after a few hours of exposure. The small features have essentially closed up with carbon deposits. The bent bars and the cracks that are visible in Fig. 7 were the result of damage caused by an earlier attempt to clean the contaminated mask with reactive ion etching in an oxygen plasma. For reflection masks the carbon contamination effect was apparent by a gradual degradation in the pattern contrast as the carbon plated out. By directing a local beam of oxygen $\left(\sim 10^{-3}\right.$ Torr $)$ at the mask the effect was reduced by more than a factor of 10 . Future work involving soft $\mathrm{x}$-ray projection lithography will necessitate the use of UHV cleaning and assembly procedures.

\section{CONCLUSION AND DISCUSSION}

We have demonstrated that this ring field optic has imaged features with $42 \mathrm{~nm}$ radiation near the diffraction limit. This implies a final wavefront error of less than $\lambda / 4$. Operating at $42 \mathrm{~nm}$ with three reffections, this translates to a 


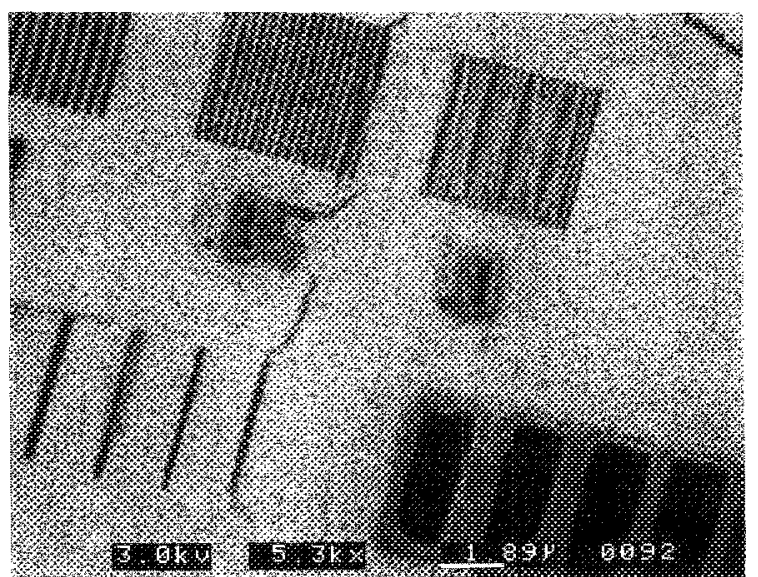

Fig. 7. SEM of the transmission mask after several hours of soft x-ray irradiation. The rather poor vacuum $\left(10^{-6}\right.$ Torr $)$ results in the cracking of the residual hydrocarbons so that carbon is plated out and the holes fill up.

rms error of less than $\lambda / 14(3 \mathrm{~nm})$ for each mirror over the total active optical area of $150 \mathrm{~cm}^{2}$. This large optical area demonstrates that it is possible to make mirrors that have close to the required figure for large optical areas. Future work will use shorter wavelengths and mirrors coated with multilayers optimized to reffect $14 \mathrm{~nm}$ radiation. Such an optic requires rms figure errors of less than $1 \mathrm{~nm}$ for each mirror. The fabrication of such large area high-quality mirrors has yet to be demonstrated. The carbon contamination problem necessitates the use of clean assembly and operating techniques. For continuous operation, as on a production line, it is likely that an in situ cleaning scheme will have to be employed to prevent the gradual degradation of the optical components. The work here has highlighted the difficulty using existing resists in this wavelength range. Future work will need to concentrate on shorter-wavelength radiation where there is less absorption which is more favorable for good exposure.

\section{ACKNOWLEDGMENTS}

The authors gratefully acknowledge the support of the staff at the Brookhaven VUV Storage Ring in providing the technical effort during the commissioning of the Undulator magnet. Special thanks is extended to $G$. Wright for his technical help in modifications to the ring field optic.

'W. T. Silfvast and O. R. Wood II, Microelectron. Eng. 8, 3 (1988).

${ }^{2}$ A. M. Hawryluk and L. G. Seppala, J. Vac. Sci. Technol. B 6, 2162 (1988).

${ }^{3}$ H. Kinoshita, K. Kurihara, Y. Ishii, and Y. Torii, J. Vac. Sci. Technol. B 7, 1648 (1989).

'J. E. Bjorkholm, J. Boker, L. Eichner, R. R. Freeman, J. Gregus, T. E. Jewell, W. M. Mansfield, A. A. MacDowell, E. L. Raab, W. T. Silfvast, L. H. Szeto, D. M. Tennant, W. K. Waskiewicz, D. L. White, D. L. Windt, and O. R. Wood I, J. Vac. Sci. Technol. B 8, 1509 (1990)

${ }^{5}$ A. Offner, Opt. Eng. 14, 130 (1975).

${ }^{6}$ O. R. Wood IT, W. 'T. Silfvast, and T. E. Jewell, J. Vac. Sci. Technol. B 7, $1613(1989)$

'D. L. Windt, W. C. Cash, M. Scott, P. Arendt, B. Newman, R. F. Fisher, and A. B. Swatzlander, Appl. Opt. 27, 246 (1988).

${ }^{8}$ A. M. Fauchet, B. C. Craft, J. N. Galayda, H. Hsieh, A. Luccio, J. B. Murphy, C. Pellegrini, A. van Steenbergen, G. Vignola, L. H. Yu, R. R. Freeman, and B. M. Kincaid, National Synchrotron Light Source Annual Report (National Technical Information Services, Springfield, 1985), p. 137.

${ }^{9}$ Calculated from absorption coeficients of B. L. Henke, J. C. Davis E. M. Gultikson, and R. C. C. Percra, "A preliminary report on $x$-ray photoabsorption coefficients and atomic scattering factors for 92 elements in the 10-10 000 eV region," LBL-26295, UC-411, 1988.

${ }^{10}$ W. M. Mansfield, J. E. Bjorkholm, R. R. Freeman, A. A. MacDowell, G. N. Taylor, L. H. Szeto D. M. Tennant, W. K. Waskiewicz, D. L. White, D. L. Windt, O. R. Wood II, R. M. D'Sousa, and A. R. Neureuther, "Effects of Absorption on Resist Performance in Soft X-ray Projection Lithography," Soft X-ray Projection Lithography, 1991, Tecknical Digest Series (Optical Society of America, Washington, DC), in press

" D. L. Windt, W. C. Cash, M. Scott, P. Arendt, B. Newman, R. F. Fisher, A. B. Swatzlander, P. Z. Takacs, and J. M. Pinneo, Appl. Opt. 27, 279 (1988). 